\title{
IN MEMORIAM JULES GRITTI
}

Depuis plus de trente ans, son œuvre balisait la recherche sur les médias, lui fournissant de précieux points de repère théoriques ou des analyses exemplaires. Et depuis le même temps, il était notre ami, celui dont la culture, l'attention, la disponibilité et la cordialité rendent les avis et conseils aussi précieux que chaleureux.

Pour les étudiants de notre département, il était ce visiteur stimulant dont le propos élargit brusquemment les perspectives.

Lorsque nous lui avons fait part de notre intention de publier un numéro sur les rapports entre l'image et la connaissance, il nous avait dit: " $\mathrm{j}$ ' ai quelques pages sur le sujet, je vous les enverrai, vous me direz...". Sans doute savait-il déjà que ces pages compteraient parmi les dernières qu'il écrirait. Maintenant que nous le savons nous aussi, nous sommes heureux de les avoir, ces pages, ultime témoignage de sa perspicacité, non seulement parce qu'elles introduisent bien à notre sujet, mais surtout parce que leur publication rend plus sensibles nos sentiments.

Recherches en communication, $\mathrm{n}^{\circ} 10,(1998)$. 